\title{
Numerical Approach for Enhanced Oil Recovery with Surfactant Flooding using STARS (CMG)
}

\author{
Brian Robin Stanislaus and Hisham Khaled Ben Mahmud \\ Department of Petroleum Engineering, Curtin University Malaysia
}

*Corresponding Author: Hisham Khaled Ben Mahmud, Department of Petroleum Engineering, Curtin University Malaysia

\begin{abstract}
There is more than half of the original oil of the reservoir which is entrapped and immobile after orthodox recovery methods (primary and secondary recovery methods). Enhanced Oil Recovery (EOR) is essential to further extract the unrecovered residual oils. There are many EOR methods available to improve oil production by injecting fluids into the reservoir. In this thesis, the EOR method used is chemical injection and the specific chemical used is surfactant. Surfactant flooding utilises surface active agents (or surfactants) to adsorb onto oil-water interface and reduce their interfacial tension (IFT) to an ultralow value of 10-2 mN/m and below. Due to the low IFT, oil is readier to be mobilised and its relative permeability with water is increased and this in turn alters the wettability of the reservoir to become more water-wet. Henceforth, more residual oil can be displaced yielding a greater oil recovery. The reservoir used in this research is an oil field located in Libya. A numerical approach simulation is done on this field using STARS which is a software package by Computer Modelling Group (CMG). From the simulations executed, primary recovery is done from 1987 till 1995 using natural depletion as the reservoir has a strong water drive. Water flooding method is simulated as the secondary recovery method from year 1995. The optimum results are obtained when water is flooded at a rate of $3000 \mathrm{bbl} /$ day and for 5 years till year 2000. From year 2000 onwards, the reservoir undergoes surfactant flooding. Sensitivity analyses are done for different surfactant concentrations, flow rates and flooding periods. From the results, surfactant is flooded for 6 years (20002006) with a flow rate of $3000 \mathrm{bbl/day}$ and concentration of $0.8 \%$ weight. It is proven that with optimum surfactant flooding conditions, an extra of 167,167 barrels of oil is recovered.
\end{abstract}

Keywords: Enhanced oil recovery, surfactant flooding, tertiary recovery, STARS, simulation, interfacial tension, EOR, IFT, and CMG.

\section{INTRODUCTION}

Crude oil serves as one of the world's most important source of energy. There are several stages in crude oil production at which crude oil is recovered. The initial stage involves the primary recovery whereby the crude oil is produced by the reservoir's natural energies like expansion, compaction, gas drive, solution gas drive and water drive. The secondary recovery includes gas and water injection to displace the oil from the reservoir to be produced. The primary and secondary recovery can only produce about one third of the original oil in place (OOIP) in the reservoir (Cooney et al., 2015). Enhanced oil recovery (EOR) is then introduced to extract more oil from the reservoir (E. Tzimas, 2005).

EOR is a common term for tertiary recovery methods that increase the quantity of crude oil that can be possibly produced from a reservoir after conventional methods of recovery. EOR methods optimise recovery of the crude oil through the application of heat, chemicals or solvents after primary and secondary recovery have been deployed (Cooney et al., 2015). Generically, according to Sara Bülow Sandersen (2012), EOR is a process whereby the external energy and materials are introduced to the reservoir to influence the interfacial tension (IFT) between oil and water, properties of the fluids, wettability conditions, forming of pressure gradients to prevail over retention and the mobilisation of crude oil.

Surfactant flooding is one of the most promising techniques in chemical EOR. To improve the recovery rate of crude oil, the dimensionless capillary number which is the ratio of viscous forces to inertial forces has to be increased (Zhang et al., 2014). In order to increase the capillary number high enough for efficient oil displacement, an ultra-low interfacial tension (IFT) about $0.001 \mathrm{mN} / \mathrm{m}$ 
between crude oil and formation water is needed to be achieved (M. Ahmadi et al., 2015). Surfactants were used in EOR since 1970's (Kamal, 2016). Surfactant is a contraction of the term surface active agent, also generically known as soap. It has the ability to adsorb onto interfaces of two immiscible phases (oil and water) and change the free energy of those interfaces (Rosen, M. J. 2012). This is because surfactants have a hydrophilic and hydrophobic group in its structure. The hydrophilic group will attract water while the hydrophobic group will attract oil reducing the IFT between the crude oil and formation water to improve the oil recovery (Morshedi et al., 2014).

It is a common believe that the lower IFT between the crude oil and formation water, the greater the percentage of oil recovery. The performance of surfactant flooding is related to the IFT between oil and water and it is affected by several parameters such as concentration of surfactants, temperature and pressure of the reservoir, and the salinity of brine water. The effect of these four parameters on IFT are studied in this research for surfactant flooding optimization. The chemicals required may be very costly too, so the economic aspect of surfactant flooding is very crucial. Thus, optimum injection of surfactants is required (Karnanda et al., 2013).

\subsection{Statement of Problem, Objectives and Limitations of Study}

After primary and secondary recovery is done, there is still up to $60 \%-70 \%$ of oil remaining in the reservoir yet to be produced (Fathadd in et al., 2010). Hence, enhanced oil recovery (EOR) or also referred to as tertiary recovery is needed to extract the balance oil in the reservoir after primary and secondary recovery, thus optimising production of crude oil. The problem arises because a large amount of petroleum resources cannot be recovered using conventional recovery methods to meet energy demands. Hence, the need of EOR. In specific regards to this thesis, EOR refers to a distinct potential approach whereby the oil field is flooded with chemical called surfactants to increase the recoverability of crude oil.

The objectives of this research are to obtain field results at optimum conditions for primary and secondary recovery, to study the effect of surfactant concentration, flow rate and period of surfactant flooding on oil recovery in a given field after water flooding, and to evaluate potential of surfactant flooding in EOR by simulating the effect of surfactant flooding on relative permeability of oil and water. In addition to that, this research aims to have a preliminary economic evaluation of the surfactant flooding process.

The main focus is to study the effect and potential of surfactant flooding in oil recovery. The relationship between the IFT and percentage of oil recovery is developed. More emphasis is put on the effect of surfactant concentration, flooding flow rate and flooding period of surfactant and how these parameters affect the amount of oil produced. This leads to the understanding of optimization of surfactant flooding. Also, to focus on is the economics of the entire process with respect to time. The limitation of the simulation is the existence of a large and active aquifer layer that lies under the reservoir. This may affect the effectiveness and efficiency of the surfactant flooding, causing loss of surfactant and thus increasing the cost for surfactant flooding.

\section{MeThOdOLOGY}

\subsection{Stars}

The STARS simulator package in CMG is widely used in the petroleum industry in this present moment. The power of this simulator in creating a model for both laboratory and field-scale while taking complicated chemical behaviours into account makes it popular in the industry (Rai et al., 2015). Up till now, there are already a few publications using STARS (CMG) software (Chaipornkaew M \& T, 2013; Santos MD, 2011). Since the 1970's publications of articles based on different simulation methods in chemical flooding has been done. Some of the articles include a onedimensional and compositional chemical flooding simulator to study additional oil recovery due to different conditions (Pope GA, 1978), study of chemical flooding using an economical model simulator (AJ, 1996), simulator for compositional chemical flooding for surfactant polymer flooding (Han C, 2007) and a vital one in surfactant flooding which is the surfactant phase behavior simulator (Najafabadi et al., 2012).

Several flooding experiments have been conducted to discover the additional oil recovery. Then, the respective experiments were simulated by STARS (CMG) software. It was found that the ultimate 
results of the simulator software and the experiments conducted matched each other, for instance the water cut and the cumulative production of oil (Rai et al., 2015). The capability to model a surfactant flooding event on a field scale can be optimised by understanding how to simulate the behaviour of surfactants during flooding in a laboratory scale.

\subsection{Building the Model}

The field that is used for the simulation is based on an oil field located in Libya. The production of this field began in November of 1987 until November of 2010, a period of 23 years. The oil field is said to have a very strong aquifer and weak oil expansion, besides having highly viscous oils. Table 2.1 describes the other essential properties of the given reservoir. Besides that, the relative permeability of oil and water at different water saturations are also given as in Table 2.2.

Table2.1. Given data for reservoir properties.

\begin{tabular}{|c|c|}
\hline Reservoir Properties & Value \\
\hline Water Density & $62.4 \mathrm{Ib} / \mathrm{cuft}$ \\
\hline Oil Density (Stock Tank) & $38.53 \mathrm{Ib} / \mathrm{cuft}$ \\
\hline Water Compressibility & $3.3 \times 10^{-6} \mathrm{psi}^{-1}$ \\
\hline Rock Compressibility & $5 \times 10^{-6} \mathrm{psi}^{-1}$ \\
\hline Water Formation Volume Factor & $1 \mathrm{RB} / \mathrm{STB}$ \\
\hline Water Viscosity & $0.7 \mathrm{cp}$ \\
\hline Oil Viscosity & $1.34 \mathrm{cp}$ \\
\hline Reservoir Temperature & $160^{\circ} \mathrm{F}$ \\
\hline Reservoir Depth & $8150-8450 \mathrm{ft}$ \\
\hline Bubble Point Pressure & $300-500 \mathrm{psi}$ \\
\hline Reservoir Pressure & 3915 psi \\
\hline Oil Formation Volume Factor & $1.18 \mathrm{Brb} / \mathrm{STB}$ \\
\hline Initial Water Saturation & 0.2 \\
\hline Initial Oil Saturation & 0.8 \\
\hline Wellbore Radius & $0.375 \mathrm{ft}$ \\
\hline Effective Drainage Radius & $3000 \mathrm{ft}$ \\
\hline GOR (Gas-Oil Ratio) & $60-205 \mathrm{scf} / \mathrm{bbl}$ \\
\hline WOC (Water Oil Contact) & $8465 \mathrm{ft}$ \\
\hline API & $36.8-38$ deg \\
\hline WAS Content & $19 \%$ \\
\hline Pour Point & $12-24^{\circ} \mathrm{C}$ \\
\hline Tar Mat & $10-30 \mathrm{ft}$ \\
\hline Oil Production Rate & 1000 bopd \\
\hline Water Cut & $50-81 \%$ \\
\hline Maximum Oil Column & $300 \mathrm{ft}$ \\
\hline Average Net Pay & $90 \mathrm{ft}$ \\
\hline Water Salinity & $180000 \mathrm{ppm}$ \\
\hline Average Spacing & $2 \mathrm{~km}$ \\
\hline $\begin{array}{c}\text { Average Flowing Well Head } \\
\text { Pressure }\end{array}$ & $800 \mathrm{psi}$ \\
\hline
\end{tabular}

Table2.2. Given data of relative permeability of oil and water.

\begin{tabular}{|c|c|c|}
\hline Water saturation, $\mathbf{S}_{\boldsymbol{w}}$ & $\begin{array}{c}\text { Relative permeability of } \\
\text { water, } \mathbf{k}_{\mathbf{r w}}\end{array}$ & $\begin{array}{c}\text { Relative permeability of } \\
\mathbf{0 i l}_{\mathbf{1}} \mathbf{k}_{\mathbf{r}}\end{array}$ \\
\hline $\mathbf{0 . 0 0 1}$ & 0.000407 & 0.995707 \\
\hline $\mathbf{0 . 0 1}$ & 0.005495 & 0.957704 \\
\hline $\mathbf{0 . 1}$ & 0.074131 & 0.635686 \\
\hline $\mathbf{0 . 2}$ & 0.162242 & 0.383078 \\
\hline $\mathbf{0 . 3}$ & 0.256535 & 0.215735 \\
\hline $\mathbf{0 . 4}$ & 0.355081 & 0.111186 \\
\hline $\mathbf{0 . 5}$ & 0.456916 & 0.050766 \\
\hline $\mathbf{0 . 6}$ & 0.56145 & 0.019447 \\
\hline $\mathbf{0 . 7}$ & 0.668284 & 0.005644 \\
\hline $\mathbf{0 . 8}$ & 0.777126 & 0.000987 \\
\hline $\mathbf{0 . 9}$ & 0.887757 & $5.01 \times 10^{-5}$ \\
\hline $\mathbf{0 . 9 9}$ & 0.988707 & $2.51 \times 10^{-9}$ \\
\hline
\end{tabular}

The reservoir model built in STARS has grid dimensions of 7 × 7 × 6 layers with a total of 294 grid blocks. Each grid block has a dimension of 315 x 315 x $50 \mathrm{ft}$. Each layer has its own unique properties as described in Table $\mathbf{2 . 3}$. 
Table2.3. Given data for the properties of each layer in the reservoir.

\begin{tabular}{|c|c|c|c|c|c|c|}
\hline & \multicolumn{6}{|c|}{ Layers } \\
\hline Properties & 1 & 2 & 3 & 4 & 5 & 6 \\
\hline Permeability, k (mD) & 17 & 68 & 30 & 286 & 74 & 64 \\
\hline Porosity, $\varphi(\%)$ & 14 & 19 & 16 & 18 & 17 & 16 \\
\hline Net to Gross, NTG & 0.5 & 0.32 & 0.38 & 0.96 & 0.72 & 0.65 \\
\hline Oil Saturation, $\mathbf{S}_{\mathbf{0}}$ & 65 & 69 & 67 & 83 & 70 & 67 \\
\hline Net Volume $\left(10^{6} \mathrm{~m}^{3}\right)$ & 50 & 1,169 & 2,502 & 3,800 & 5,232 & 1,462 \\
\hline Pore Volume, PV $\left(10^{6} \mathrm{rm}^{3}\right)$ & 7 & 209 & 445 & 692 & 822 & 251 \\
\hline $\begin{array}{c}\text { Hydrocarbon Pore Volume, } \\
\text { HCPV oil }\left(10^{6} \mathrm{rm}^{3}\right)\end{array}$ & 3 & 97 & 187 & 433 & 407 & 68 \\
\hline $\begin{array}{l}\text { Stock Tank Oil Initially In } \\
\text { Place, STOIIP (Mstb) }\end{array}$ & 13 & 516 & 994 & 2,308 & 2,170 & 359 \\
\hline $\begin{array}{c}\text { Average NTG above Oil-Water } \\
\text { Contact, OWC }\end{array}$ & 0.28 & 0.28 & 0.47 & 0.95 & 0.8 & 0.9 \\
\hline $\begin{array}{c}\text { Average } \varphi \text { above Oil-Water } \\
\text { Contact, OWC }\end{array}$ & 0.14 & 0.18 & 0.18 & 0.18 & 0.16 & 0.17 \\
\hline $\begin{array}{c}\text { Average So above Oil-Water } \\
\text { Contact, OWC }\end{array}$ & 0.43 & 0.46 & 0.42 & 0.63 & 0.5 & 0.27 \\
\hline $\begin{array}{c}\text { Average Sw above Oil-Water } \\
\text { Contact, OWC }\end{array}$ & 0.57 & 0.54 & 0.58 & 0.37 & 0.5 & 0.73 \\
\hline
\end{tabular}

\subsection{Well Completion Strategy}

Once the reservoir model is set up, the well completion takes place. Vertical wells in a five spot pattern are used to carry out the simulation. This is because the five spot pattern is the most popular well pattern used in the industry. The nearest flow path is straight line between the production well and the injection well which means it is a strongly conductive pattern. In addition to that, it gives a good areal sweep efficiency and is the most economical well pattern (Smith, \& Cobb, 1997).

The inverted five spot pattern has the water injected from the injector right in the centre. This way water is equally spread out to the 4 producer wells at the corners. The water injected sweeps the oil left behind in the reservoir starting from the center all the way to the four corners to be produced in the wellbore. It produces better production of oil as negligible amount of water is wasted into the formation of reservoir with no hydrocarbon to be produced. Reservoir pressure may be raised effectively. Hence, the inverted five spot pattern (Figure 2.1) promotes better oil recovery and the simulation is proceeded by having a single injector at the centre and four producers at the corners.

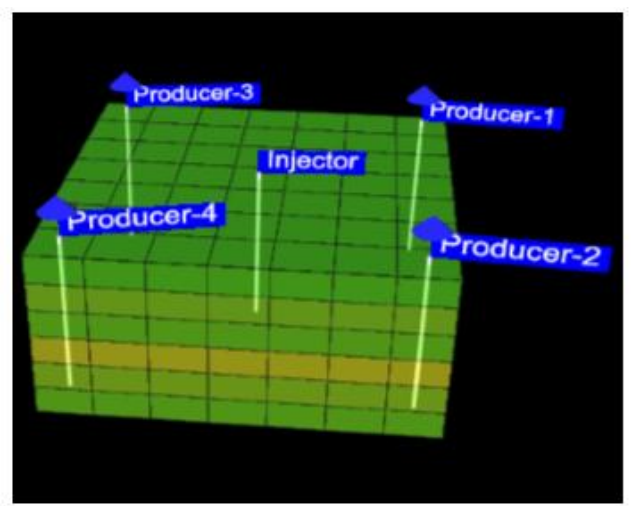

Figure2.1. Well pattern of an inverted five spot pattern extracted from STARS

\subsection{STARS Simulation Stages}

After the well pattern has been finalised, production is set to take place. The first simulation stage for the oil field uses the reservoirs natural energy for production. There is no injection of any fluid into the reservoir. The reservoir is set to produce from the four producing wells. This primary recovery stage analyses the optimum layers to produce from to achieve the best water cut $\%$, oil production rate and oil recovery. After optimum conditions have been determined from primary recovery, water is injected as a method of secondary recovery for the oil. At this point, the best water flooding period and injection flow rate is determined with respect to oil production rate and oil recovery, without 
neglecting reservoir pressure monitoring. After primary and secondary recovery stages are executed, surfactants are introduced into the reservoir to enhance the recovery of oil even further. Simulations are done for different surfactant concentrations, different flow rates and different periods. With the optimum conditions for surfactant flooding, the results of ultimate oil recovery are analysed and justified.

\subsection{Assumptions}

Several assumptions were made prior to running the simulation using STARS to gain a more direct approach in the observation of the results yielded. These are:

1. The reservoir has two phases which are the oil phase and the water phase.

2. Three elements are taken into considerations and those are oil, water and surfactants. The amount of free gas is considered zero.

3. Adsorption of surfactants is ignored.

4. Two-dimension system that has uniform properties with no geological complexities.

5. Salinity effect on phase behaviour is ignored.

6. Chemical reactions do not take place in the system.

7. The flow of oil and water obeys Darcy's Law.

\section{RESUlTS \& DisCUSSION}

\subsection{Primary Recovery (Altering Producing Layers)}

A sensitivity analysis is done to obtain the best layers to produce from. Based on Figure 3.1, the water cut \% reaches $80 \%$ within the span of two years after the start of production in Case 1 where all the layers are set to produce. This is a high amount in a short amount of time. The water in the reservoir is highly saline with salinity of $180000 \mathrm{ppm}$. Producing this water too early may be detrimental as it may corrode and damage the bottom hole and surface equipments and this may cost a lot of money. Following from this, layer 6 is closed in Case 2. This is because layer 6 is the closest to the aquifer at the bottom and the aquifer in this reservoir is highly active. Hence, layer 6 is closed in efforts of trying to reduce the amount of water being produced from the reservoir. However, the results of water cut \% shows similar results to that of Case 1.Consequently, in Case 3 layer 4 is closed together with layer 6 . This is done because layer 4 has the highest permeability and water may be flowing readily through this layer into production. From the results, the water cut $\%$ reaches $80 \%$ at the same time to previous cases although it shows a slight dip in the later stages. Further efforts of trying to reduce water cut is done in Case 4 by closing perforations at layer 5 as alongside layer 4 and layer 6 . This is done as layer 5 has the second highest permeability and closer to the aquifer than any other layers that are open. The result shows that water cut $\%$ is delayed by almost one year to reach 80 $\%$. In Case 5, producing from the top two layers only gives the best results in terms of water cut $\%$.However, based on Figure 3.2 about 100,000 barrels of oil are lost by producing from only layers 1 and 2.

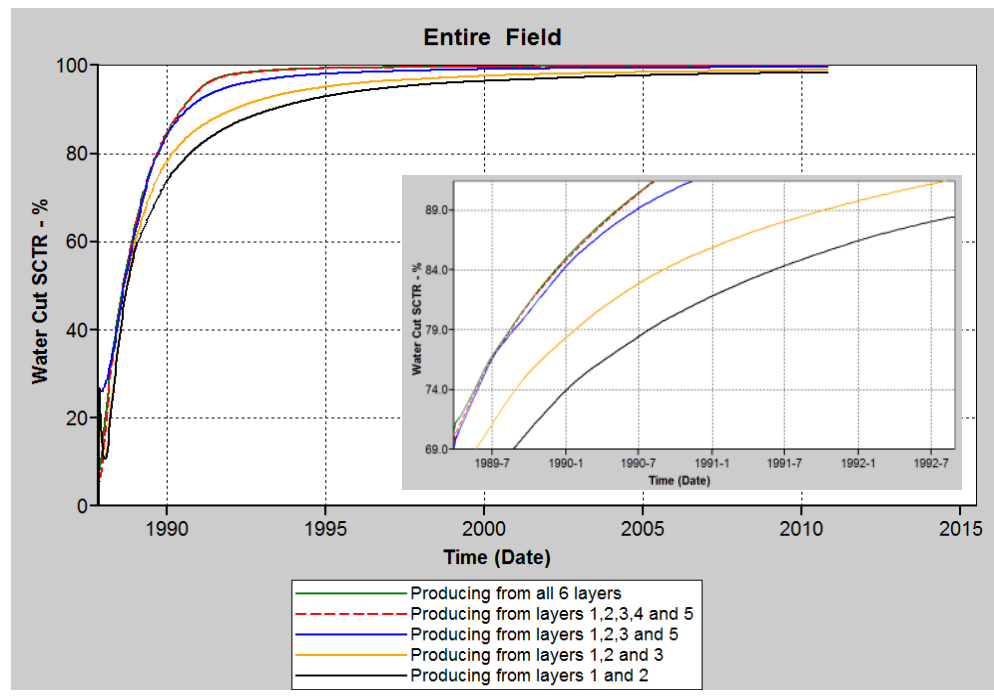

Figure3.1. Plot of water cut \% for different producing layers. 


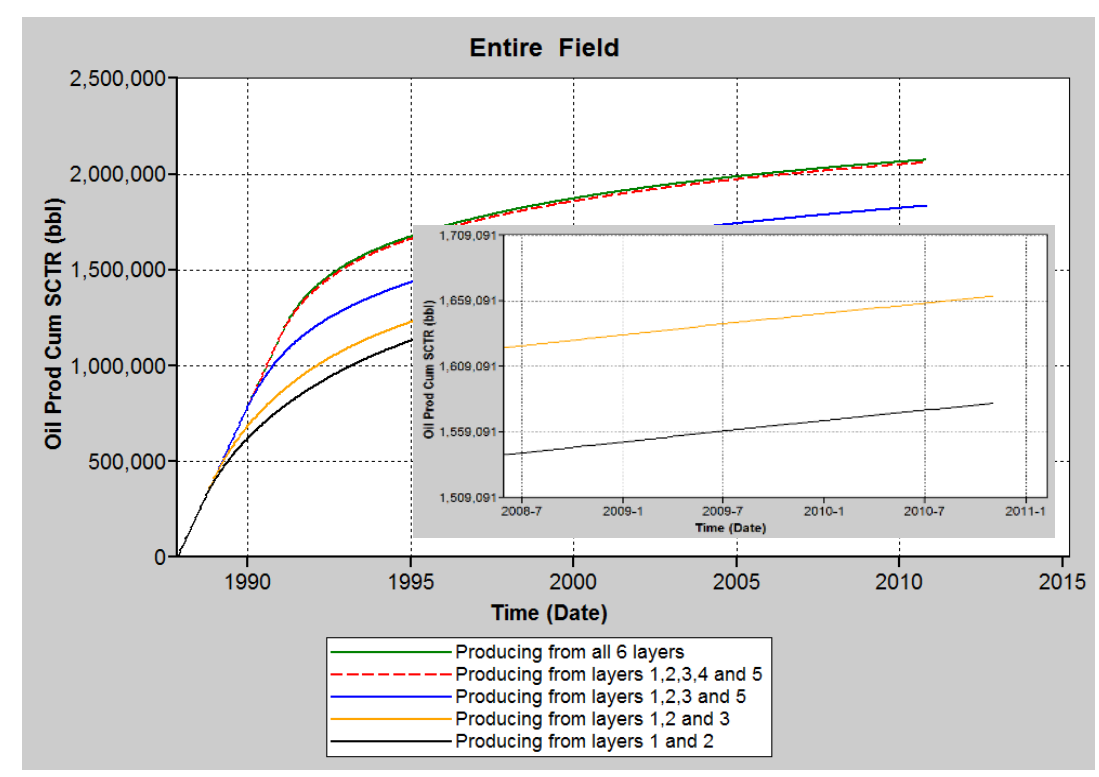

Figure3.2. Plot of cumulative oil production for different producing layers

Conclusively, Case 3 is selected and the well is to produce from layers 1, 2 and 3 only. This is aligned with the efforts of trying to reduce water cut $\%$ and at the same time, to not compensate too much of oil being recovered. Refer to Figure 3.3.

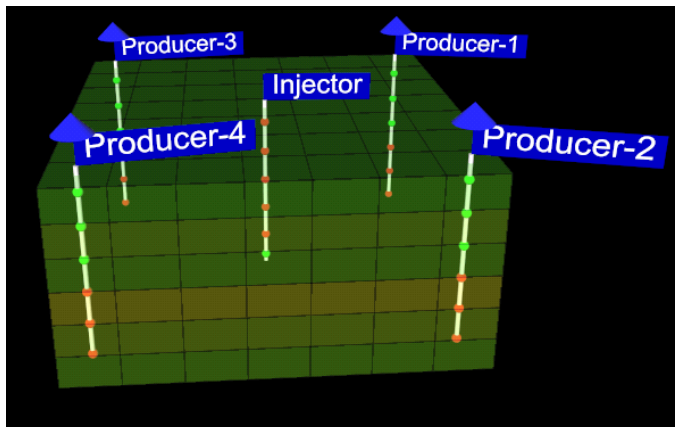

Figure3.3. Extraction from STARS-Reservoir production from layers 1, 2 and 3

\subsubsection{Optimisation Plan}

Figure 3.4 below shows the oil production rate when the well is produced from different set of layers. The oil production rate for each of the cases becomes similar to each other from year 1995 onwards and it is close to a constant gradient. Efforts are made to improve the oil production rate from this period of production.

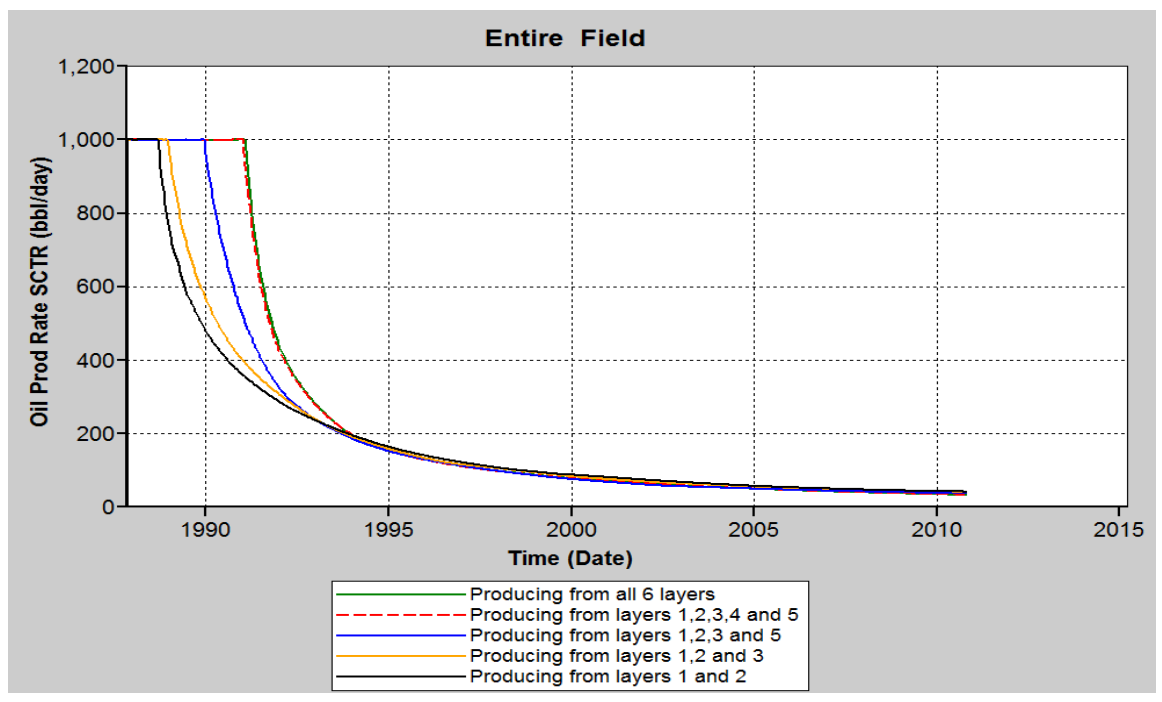

Figure3.4. Plot of oil production rate for different producing layers 
Referring to Figure 3.1 previously, the water cut $\%$ of the different cases is not much different to each other from year 1995 to 2000 . Therefore, layer 5 is opened for production from year 1995 onwards. This is to help increase the oil production rate and recover more oil from this layer. From year 2000 till 2005, the water cut \% is even more alike to each other. Hence, layer 4 is set open from year 2000 onwards to spike the production rate and increase oil recovery as this layer contains the most amount of oil saturation and has the highest permeability. Furthermore, from year 2005 onwards, layer 6, the closest to the aquifer is set open because the strength of the aquifer would have been significantly reduced by this time. From this juncture, the production occurs from all six layers. These efforts reflect in a significant increase of oil recovery. The difference of oil recovered from producing from layers 1, 2 and 3 till the end of the well life and producing based on the optimization plan, records an increase of $10 \%$ (Figure 3.5). Moreover, there are significant peaks in the oil production rate based on Figure 3.6. which is a highly favorable event. Ultimately, the simulation is set to run with an inverted five spot well pattern and set to produce from layers 1, 2 and 3 only from year 1987 to 1995. From year 1995 onwards, reservoir is produced from layers 1, 2, 3 and 5. Then from year 2000 onwards, production from layers 1, 2, 3, 4 and 5 and finally in the last five years, the well is produced from all six layers.

The percentage of oil being recovered after primary recovery is expected to be less than one third of the original oil in place (OOIP). However, after optimization of production in this reservoir, the primary recovery is able to produce $55 \%$ of OOIP. The main contributor to this result is the strong aquifer drive in the reservoir which also accounts for the high water cut $\%$.

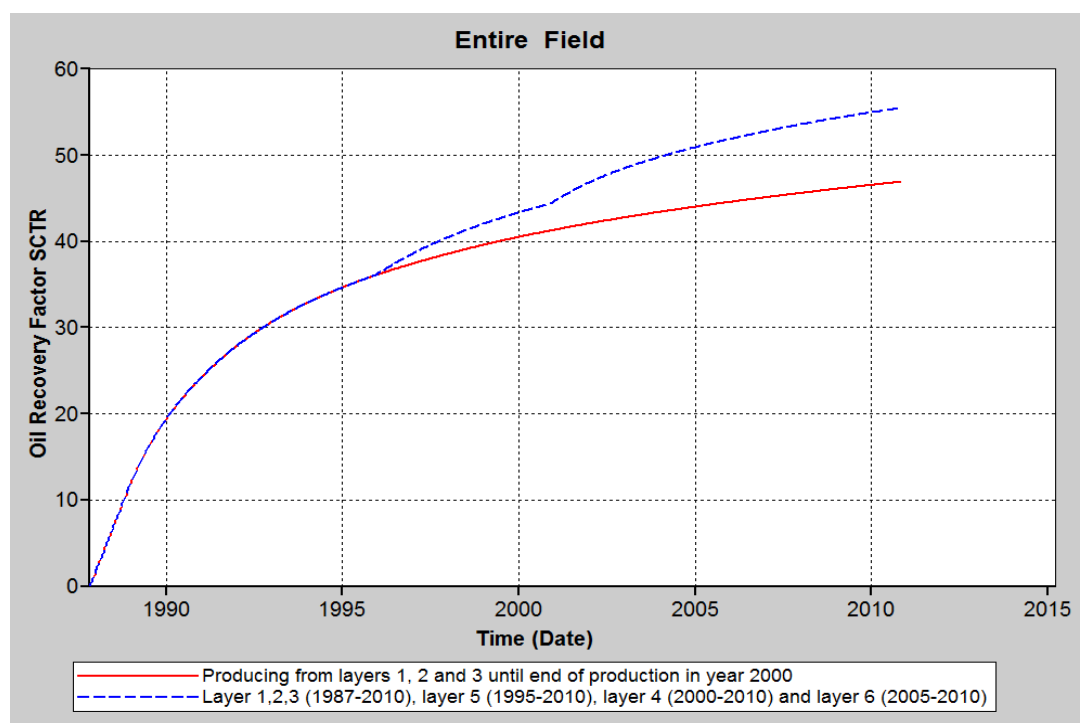

Figure3.5. Plot of oil recovery factor for production optimisation for different producing layers.

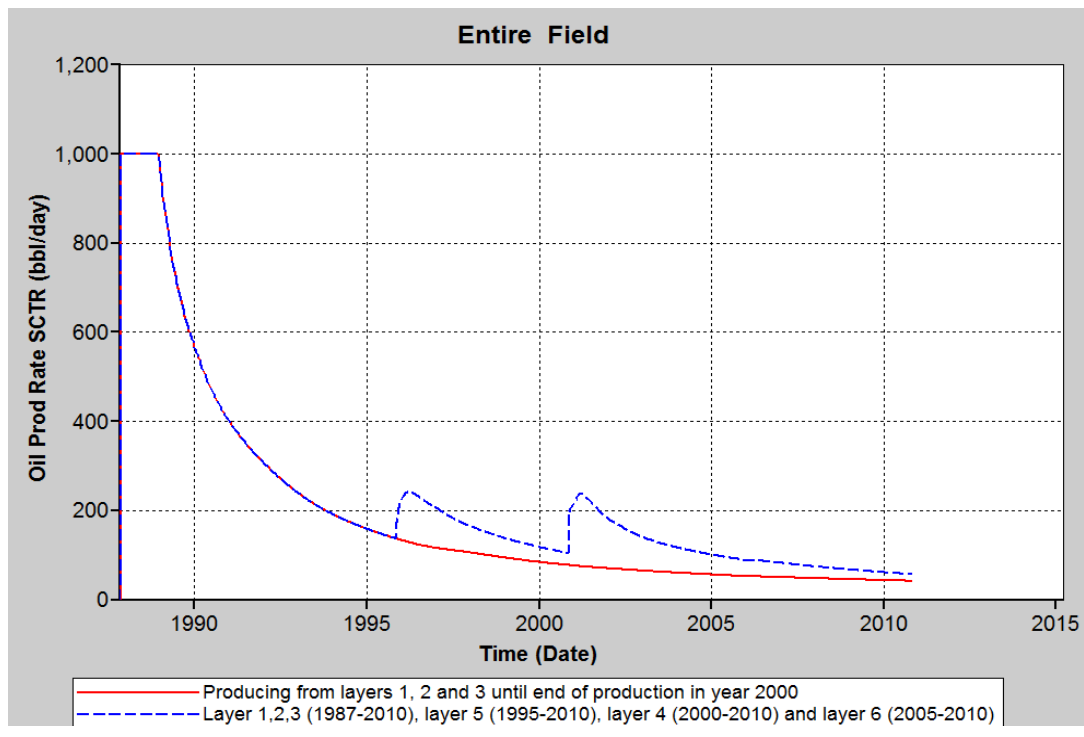

Figure3.6. Plot of oil recovery factor for production optimisation for different producing layers 


\subsection{Secondary Recovery (Water Flooding)}

After oil recovery by the reservoir's natural energy, secondary recovery takes place to produce the oil left behind using water flooding method. Water flooding is done from year 1995 onwards as the oil production rate is very low at about $250 \mathrm{bbl} / \mathrm{d}$ (Figure 3.6). Water flooding is done prior to surfactant flooding to help spike the production rate and increase the oil recovery as much as possible before proceeding to enhanced oil recovery methods. Three cases are simulated to obtain optimum conditions for water flooding which are water flooding from year 1995 onwards with flowrates of $1000 \mathrm{bbl} /$ day, $3000 \mathrm{bbl} / \mathrm{day}$ and $5000 \mathrm{bbl} /$ day. The results are contrasted with no water flooding condition.

Before analysing the results of the simulation, the initial condition of the reservoir is determined. Based on Table 2.2, the relative permeability of oil and water against water saturation is plotted as shown in Figure 3.7. From previous studies, it is deduced that the reservoir of the field is highly oilwet condition as the relative permeability of water is very high. This means that the rock formations are strongly wet with oil.

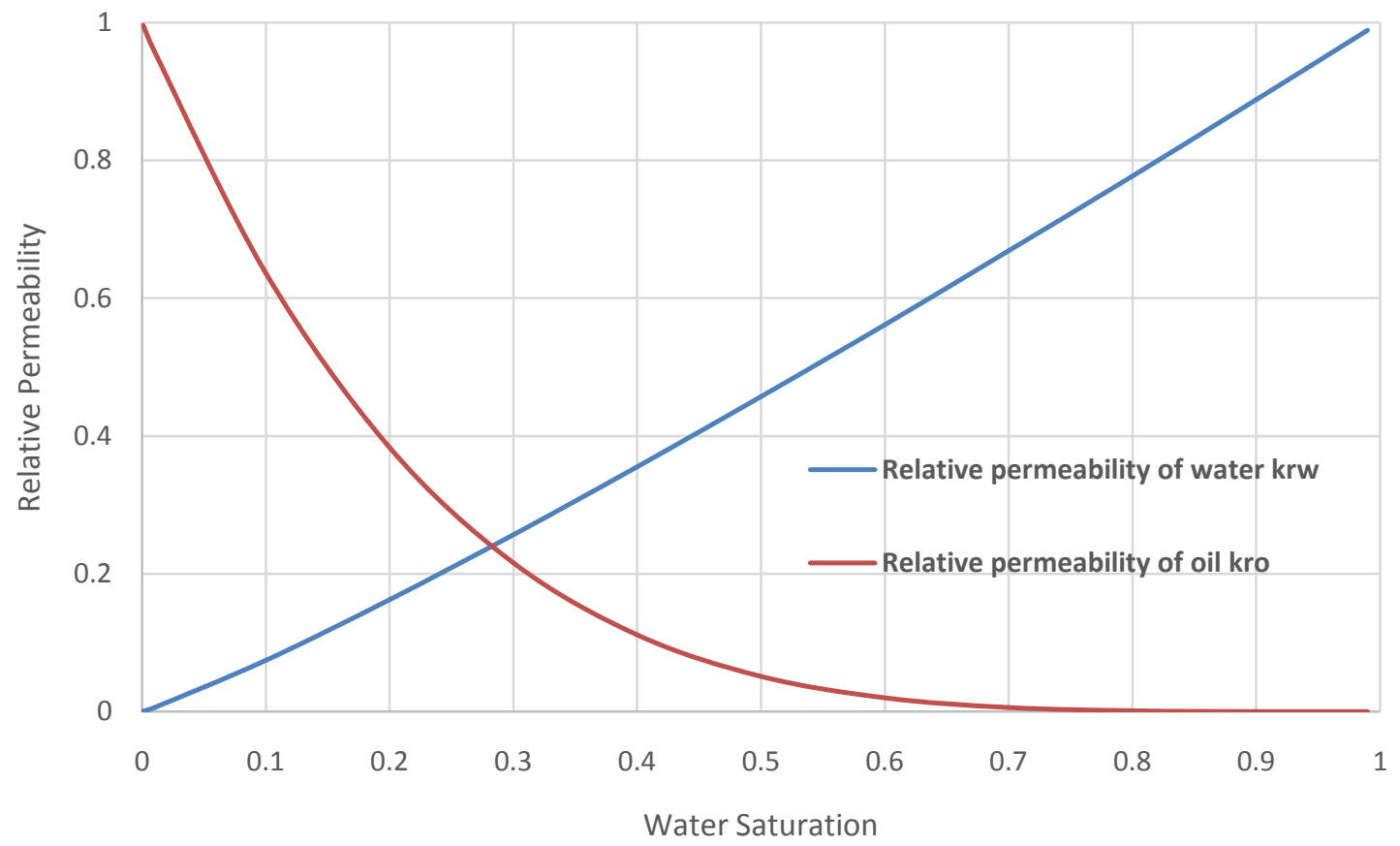

Figure3.7. Relative permeability curves of water and oil for the given oil field.

Water injection increases the reservoir pressure in order to displace the residual oil into production. According to Figure 3.8, the higher the flow rate of the water injection the higher the reservoir pressure. With a higher pressure, more residual oil can be swept towards the wellbore for production and this is reflected to a greater oil recovery as can be seen in Figure 3.9.However, the simulation result shows that the initial pressure of the reservoir has just been exceeded when the water is injected with a flow rate of $5000 \mathrm{bbl} / \mathrm{day}$. This is unwanted as it may cause problems to the hydrocarbon bearing formations and also bring negative effects to the wellbore stability. Besides that, the flow rate of water at $5000 \mathrm{bbl} /$ day requires a bigger pump capacity which costs a lot of money.

Referring to Figure 3.10 when the water flooding is injected in November 1995, there is an increase in the oil production rate as more residual oil is produced after primary recovery. Higher injection rate of water produces higher production rate. However, from November 2000 onwards an adverse result is experienced as production rate eventually drops lower than production rate of primary recovery (no water flooding).This occurrence is due to the mobility ratio, $\mathrm{M}$ where it is expected to be a value of more than one, whereby viscous fingering takes place. From previous justifications, the formation is proven to be in oil-wet condition. This means that water flooding is restricted by the capillary forces. The oil is adhered to the rock surface and this adhesion force makes it difficult for the water to flow forward along the pores. In addition to that, the oil in the reservoir has a very high viscosity of 1.34 cP. This will render the water to finger through the oil and flow down the center of the pores. 


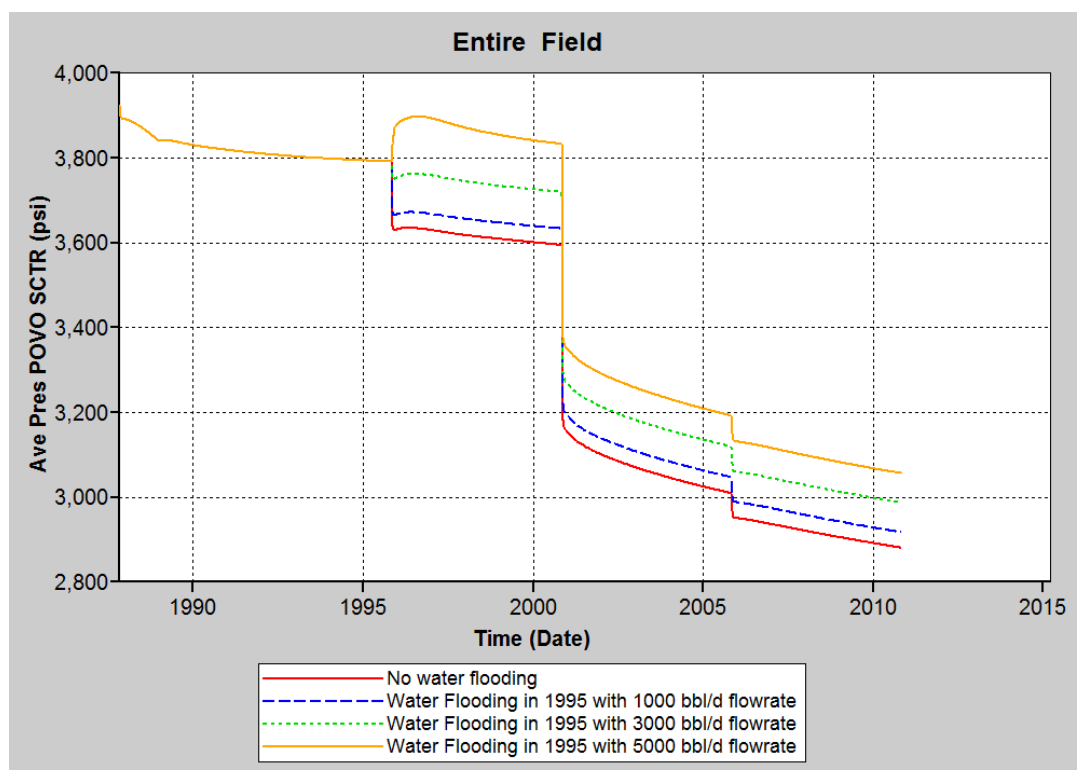

Figure3.8. Plot of average reservoir pressure for different water flooding flow rates.

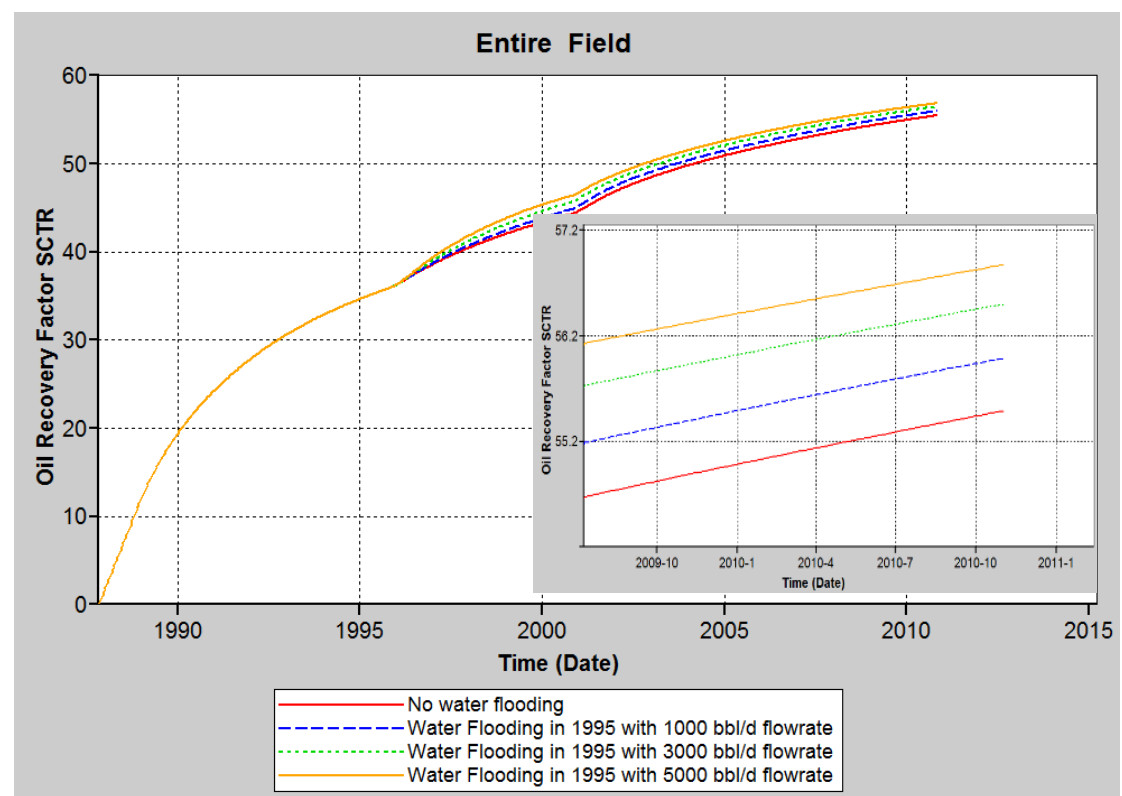

Figure3.9. Plot of oil recovery factor for different water flooding flow rates

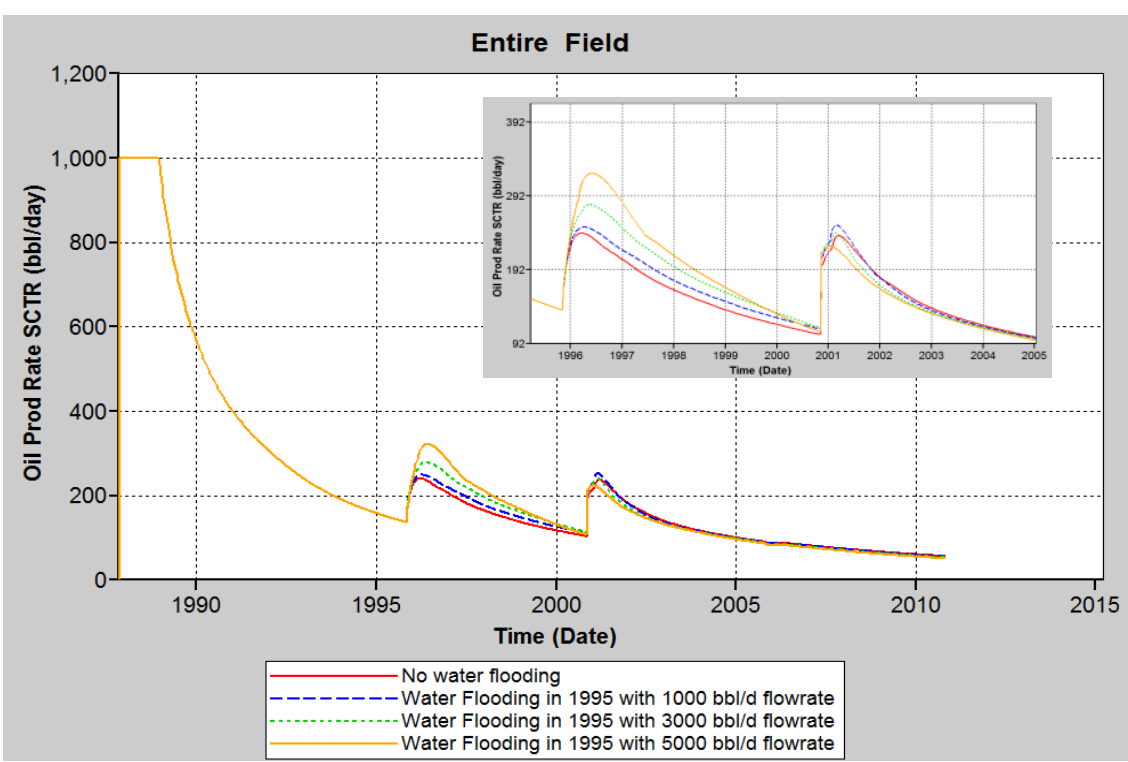

Figure3.10. Plot of oil production rate for different water flooding flow rates. 
The water fingering effect increases with the flow rate of water injected. This is manifested in Figure 3.11 as the water production increases with higher water flooding rate after November 2000. As a result, the crude oil films are left on the walls of the pores. Higher oil viscosity results in a higher mobility ratio which is unfavourable. Under primary recovery, the reservoir pressure declines from about 3900 psi to about 2900 psi over a period of 23 years. This equals to a drop of only 44 psi in a year. Furthermore, the bubble point pressure of the reservoir is given as $300-500$ psi. This means that the oil in the reservoir is still very highly in single phase and the pressure of the reservoir is still considered very high after production. This explains why water flooding is not so significant in the given oil field as water flooding aids in oil recovery by increasing the pressure of the reservoir. The small increase in oil recovery $\%$ using water flooding methods is also caused by the high oil viscosity which negatively affects the mobility ratio.

However, the reservoir is still chosen to undergo water flooding up till a certain period as it spikes the oil production rate which accounts for a greater economic return at that point of time. From the discussions above, it is concluded that the optimum water flooding rate is $3000 \mathrm{bbl} /$ day to maintain pressure below initial reservoir pressure and the optimum period of water flooding is from November 1995 and stopped in November 2000 to avoid viscous fingering effects of water.

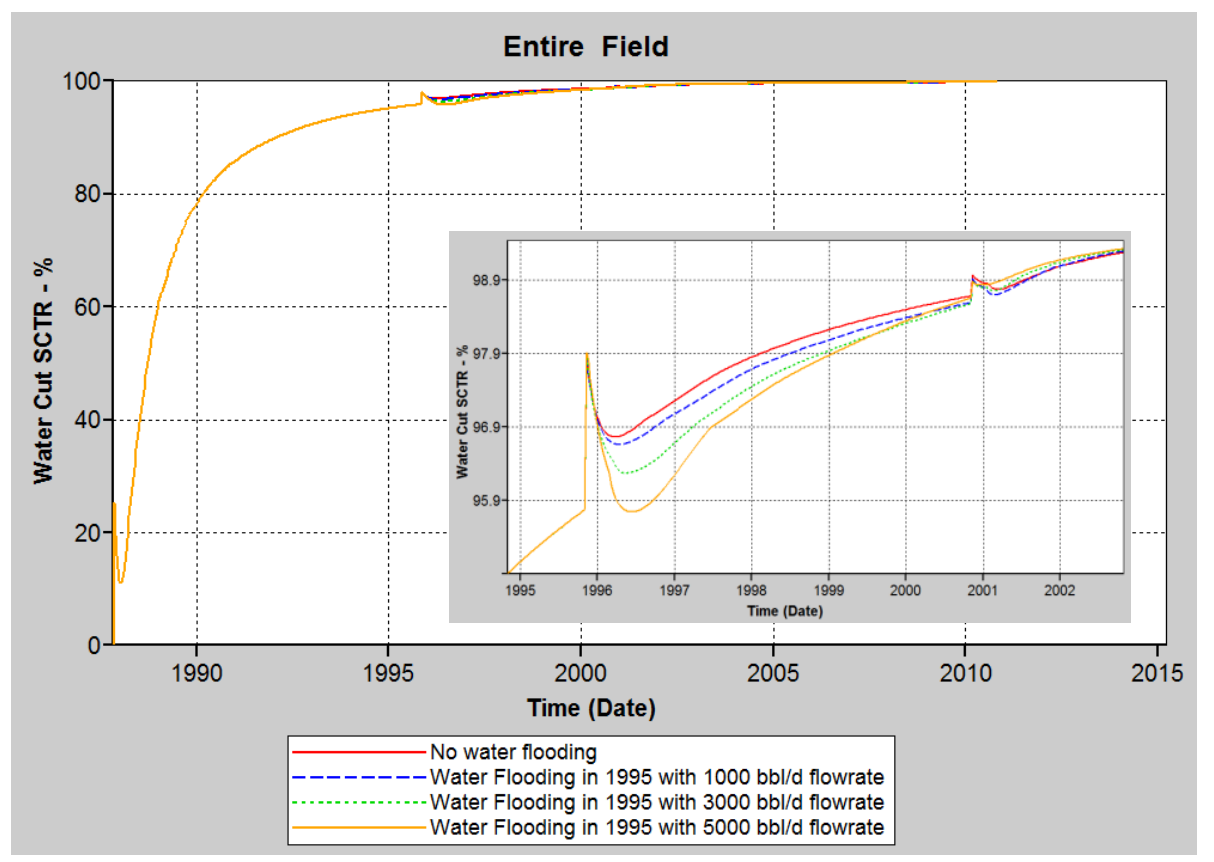

Figure3.11. Plot of water cut \% for different water flooding flow rates.

\subsection{Enhanced Oil Recovery (Surfactant Flooding)}

The injection of surfactants into the reservoir begins after water flooding method, does not benefit to the oil production rate and total oil recovery. Hence, surfactant flooding is done from November of 2000 onwards to produce as much residual oil left in the reservoir as possible.

\subsubsection{Surfactant Concentration}

It is understood that by lowering the interfacial tension (IFT) between two phases of oil and water, the effectiveness of surfactant flooding will improve, thus in turn generating a greater oil recovery percentage and cumulative oil production. In this case of EOR in oil fields, the IFT must be lowered to an ultra-low value of about $10-2 \mathrm{mN} / \mathrm{m}$ to $10-3 \mathrm{mN} / \mathrm{m}$ or lesser. This section will deal with how the concentration of surfactants will influence the IFT values and also the oil recovery. In connection to Ahmadi et al., (2013), the overall recovery of oil increases with the increase of surfactant concentration. This relationship is with respect to the IFT reduction. The higher the concentration of surfactants, the lower the IFT between oil and water thus yielding a greater oil recovery. Figure 3.12 shows the relationship between the surfactant concentrations (weight \%) and the interfacial tension (dyne/cm). This result is produced from STARS software itself. The unit dyne $/ \mathrm{cm}$ can be treated similarly to $\mathrm{mN} / \mathrm{m}$, as both has the same value. This is noted as the interfacial tension in the previous parts of the thesis is referred using $\mathrm{mN} / \mathrm{m}$ units. 


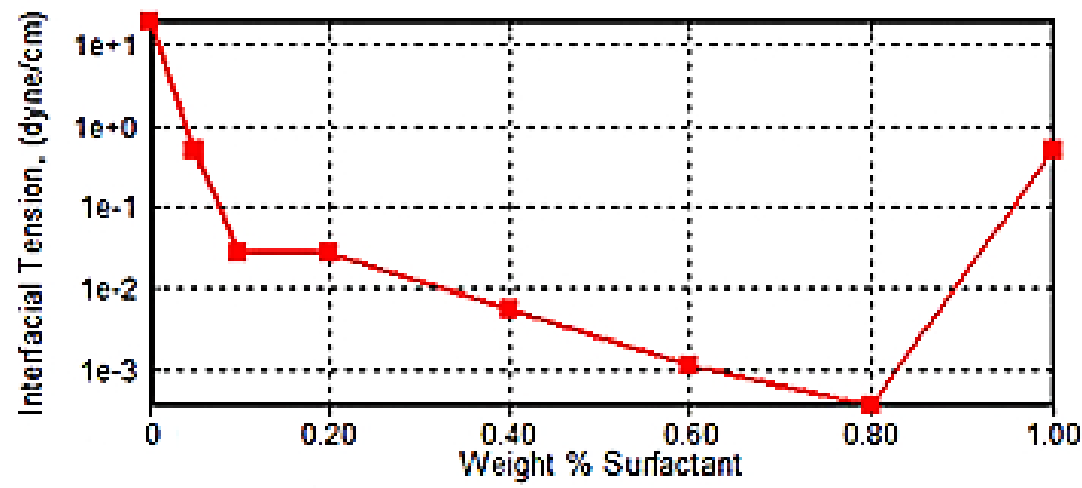

Figure3.12. Relationship between surfactant concentration and interfacial tension from STARS

Based on Figure 3.12, the general rule of increasing surfactant concentration to reduce IFT is not harmonised and matched perfectly. When the surfactant concentration exceeds $0.8 \%$, the interfacial tension increases instead of decreasing further. This is because, higher concentrations of surfactants will cause a ramification of distribution change of surfactant molecules in the interface of oil and water and this may lead to overly strong emulsification (Yuan et al., 2015).

If emulsification occurs too strongly especially when a high surfactant concentration is present, then it produces an unwanted result of yielding lower oil recovery. In view of that, only certain amounts of residual oil may be displaced in emulsion form, leaving behind the rest and causing lower than expected amount of oil recovered. Based on this result, the balance between ultralow IFT and emulsification must be balanced to optimise oil recovery using surfactant flooding. However, according to the capillary number theory, in reducing residual oil saturations and improving oil production, reduction of IFT between oil and water is still pivotal and more effective than the factor of emulsification (Yuan et al., 2015).

Henceforth, the sensitivity analysis done for the simulation limits the surfactant concentration up to $0.8 \%$ weight only as a value higher to this will produce unwanted results towards oil recovery. To study the effect of surfactant concentration on the oil recovery in the given field, different concentrations of surfactants $(0.1 \%, 0.25 \%, 0.5 \%$ and $0.8 \%$ weight $)$ are injected into the reservoir from the year 2000 onwards with a constant flowrate of $1000 \mathrm{bbl} /$ day. At the final year (2009 to 2010), chase water is introduced to the reservoir with injection rate of $3000 \mathrm{bbl} / \mathrm{day}$.

Based on Figure 3.13, injecting surfactant into the reservoir generally increases the amount of oil that is recovered from the reservoir compared to primary recovery (natural depletion water drive) and secondary recovery (water flooding). Increasing the surfactant concentration increases the amount of oil that is recovered. This happens because, as the surfactant concentration increases, more and more surfactant monomers are available to adsorb onto the interface between the crude oil and the formation water and reduce the interfacial tension. When IFT is reduced to an ultralow value, the adherence of oil to water is very low, thus increasing the efficiency of oil displacement.

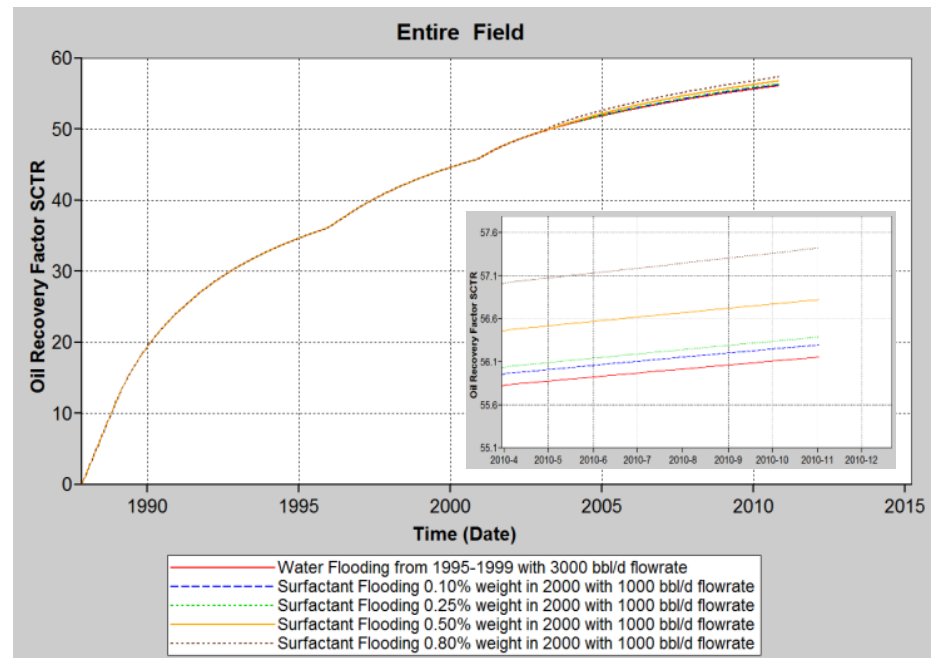

Figure3.13. Plot of oil recovery factor for different surfactant concentrations 
After the reservoir undergoes water flooding at optimum condition, only $56.3 \%$ of oil is recovered. However, when the surfactant is injected, oil recovery may rise up to $57.4 \%$ depending on the surfactant concentration. The percentage increase of oil recovery may seem small but referring to Figure 3.14, an extra of 40,000 barrels of oil is produced.

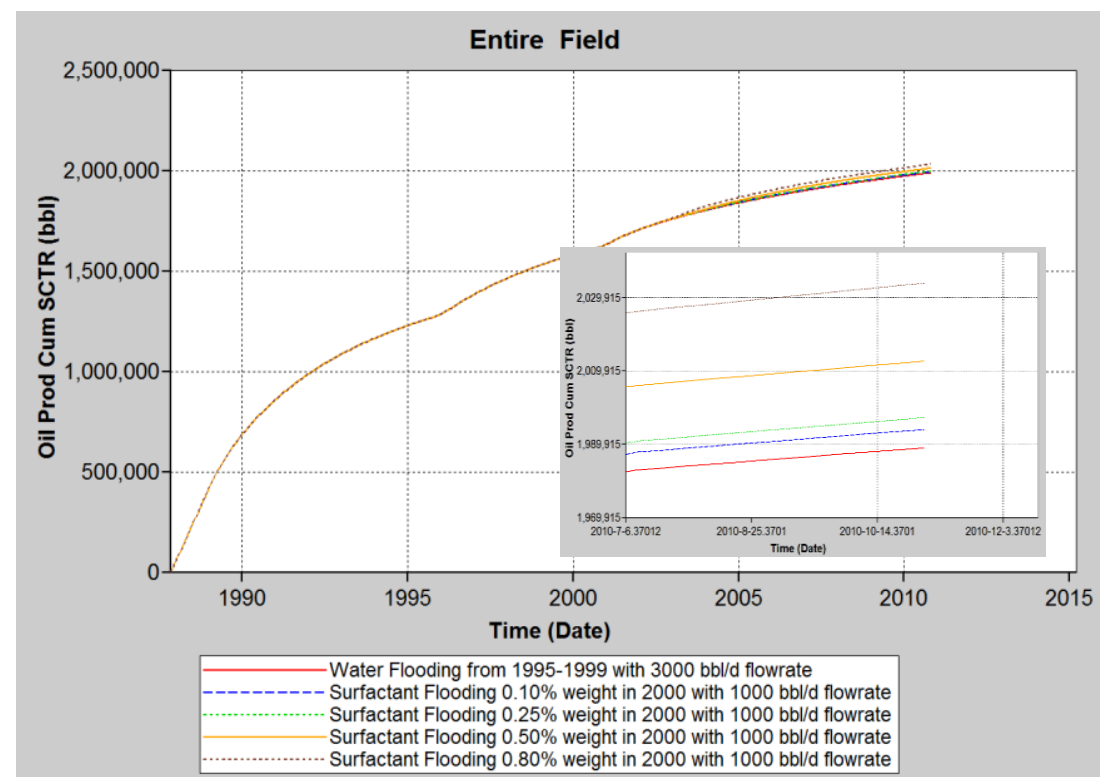

Figure3.14. Plot of cumulative oil production for different surfactant concentrations

\subsubsection{Surfactant Flooding Flow Rate}

Keeping the surfactant concentration and period of injection constant at $0.8 \%$ weight and year 2000 onwards respectively, different injection flowrate is simulated to monitor its effects on oil recovery. Flowrates used were from $1000 \mathrm{bbl} /$ day to $3000 \mathrm{bbl} /$ day with increaments of $500 \mathrm{bbl} / \mathrm{day}$.

As depicted in Figure 3.15, a higher injection rate yields a higher percentage of oil recovery. For every $500 \mathrm{bbl} / \mathrm{day}$ increase of injection rate, there is about $1 \%$ increase of oil recovered. However, surfactants are injected up to a certain extent of flow rate only due to technical aspects. Greater than this rate requires more cost as a bigger pump is required to pump liquids at a higher rate. Besides that, according to Jin et al. (2014), if the flow rates are too high, a drop in oil recovery is experienced. This is due to the fact that high flow rates will impose shear effects on the molecules of the surfactant, reducing its efficiency. Hence, for all cases the sensitivity analysis for the flow rate simulated in the software does not exceed $3000 \mathrm{bbl} / \mathrm{day}$.

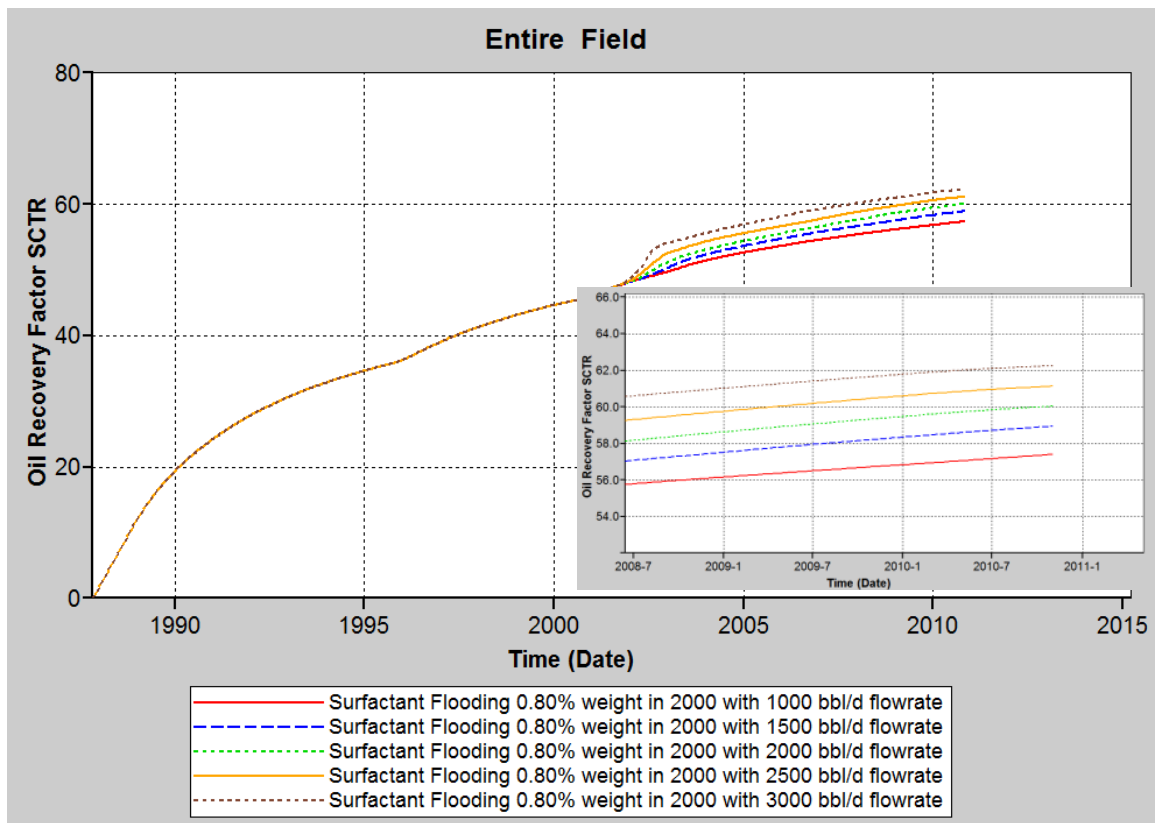

Figure3.15. Plot of oil recovery factor for different surfactant flooding flow rates 
The flow rate of surfactant flooding is related to the capillary number. This brings into play the role of capillary number into the picture. The capillary number is given in Eq. (3.1) where, Nc is the dimensionless capillary number, $\mathrm{v}$ is the Darcy velocity $(\mathrm{m} / \mathrm{s}), \mu$ denotes the displacing fluid viscosity (Pa.s) and $\sigma$ represents the interfacial tension (N/m) (Aslam, 2010).

$N_{c}=\frac{v \mu}{\sigma}$

In the simulation using STARS (CMG), viscosity and IFT are kept constant by using surfactant concentration of $0.8 \%$ weight for all cases. This is done to study the effect of velocity on the percentage oil recovered and the cumulative oil production. As flow rate increases, the velocity of the fluid increases. Thus, when applied to the Eq. (3.1), yields a higher result in capillary number. Based on past studies, when capillary number is made greater, displacement of oil is greater and it reduces the residual oil saturation, thus increasing the percentage of oil recovery which accounts for better cumulative oil production. Referring to Figure 3.16, flow rate of $3000 \mathrm{bbl} / \mathrm{day}$ in Case 5 is able to produce a cumulative oil production of about 2.2 Million barrels.

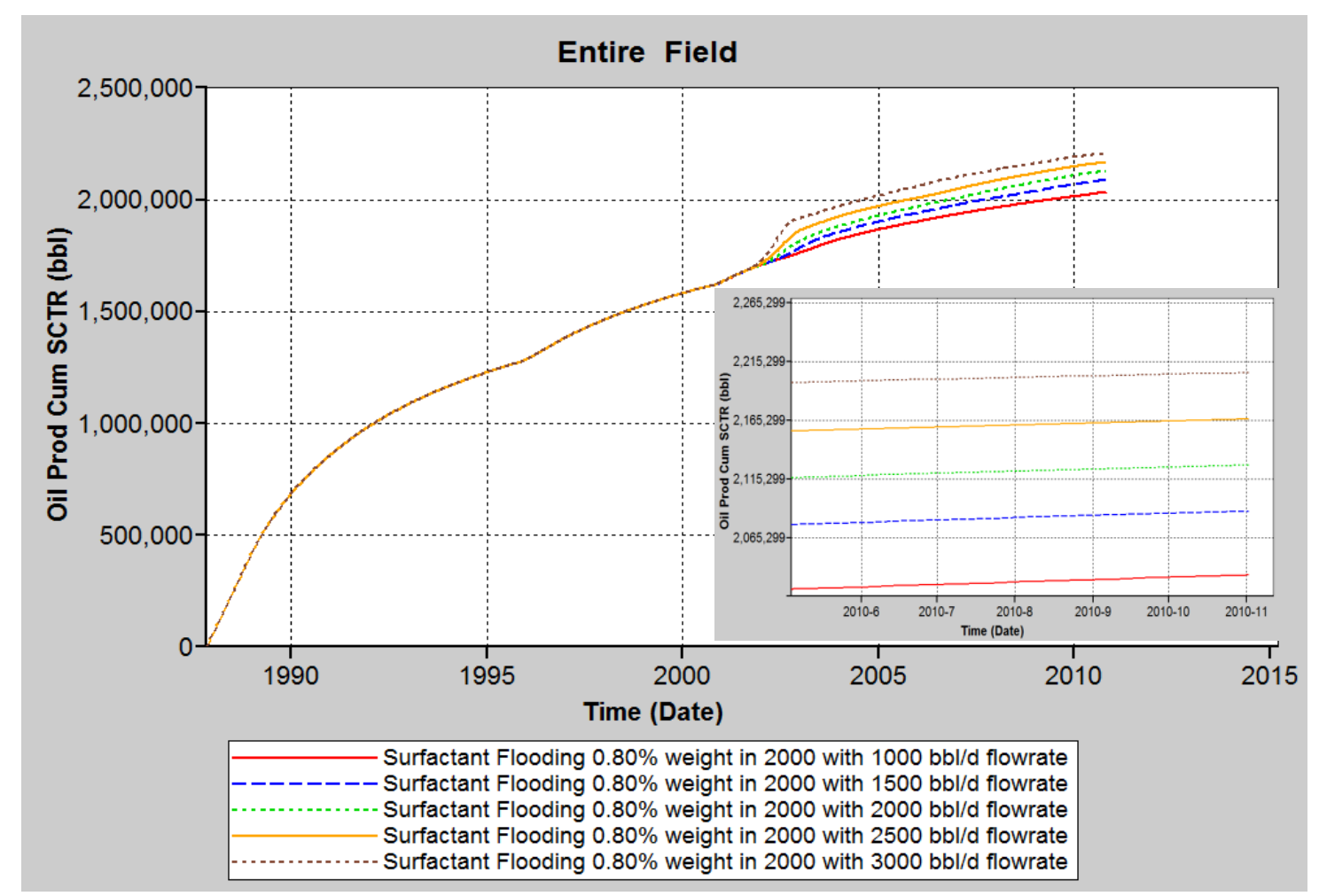

Figure3.16. Plot of cumulative oil production for different surfactant flooding flow rates

The flow rate also affects the spike in oil production as well (Figure 3.17). The greater the flow rate of surfactants being injected into the reservoir, the greater the oil production rate. For a flow rate of 3000 $\mathrm{bbbl/day,} \mathrm{the} \mathrm{oil} \mathrm{production} \mathrm{rate} \mathrm{reaches} \mathrm{close} \mathrm{to} 1000 \mathrm{bbl} / \mathrm{day}$. This is favourable as the reservoir given is expected to produce oil at this rate. Also, for lower flow rates, it can be seen that the effect on oil production rate takes longer. For example, the spike to oil production rate occurs in July 2001 for the flow rate of $3000 \mathrm{bbl} /$ day whereas for the flow rate of $2000 \mathrm{bbl} /$ day the spike is only experienced in January 2002. The difference in time of the spike is due to the volume. Certain amount of surfactant is needed until it can effectively react with the oil in the reservoir to cause a significant change in the production.

Given that the period of injection of surfactant is constant for all cases, which is from year 2000 onwards, the effect of volume of surfactants can be evaluated. Higher flow rate means higher volume. Thus, it is wise to conclude that the greater the volume of surfactants injected, the greater the oil recovery. 


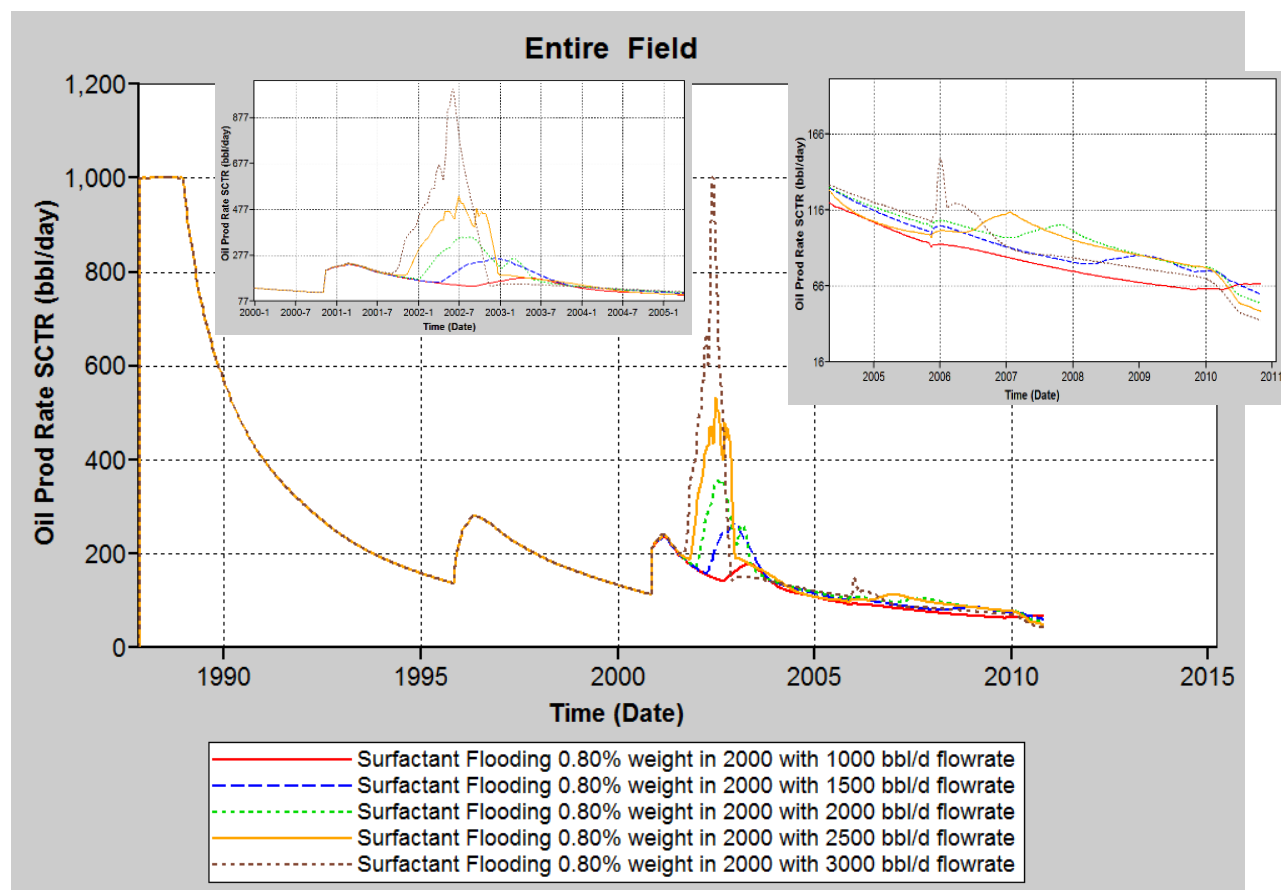

Figure3.17. Plot of oil production rate for different surfactant flooding flow rates

In addition to that, surfactant flooding can also aid in reducing the water cut $\%$. For a flow rate of $3000 \mathrm{bbl} /$ day and surfactant concentration of $0.8 \%$ weight, it is possible to reduce water production about $3 \%$. Refer to Figure 3.18.

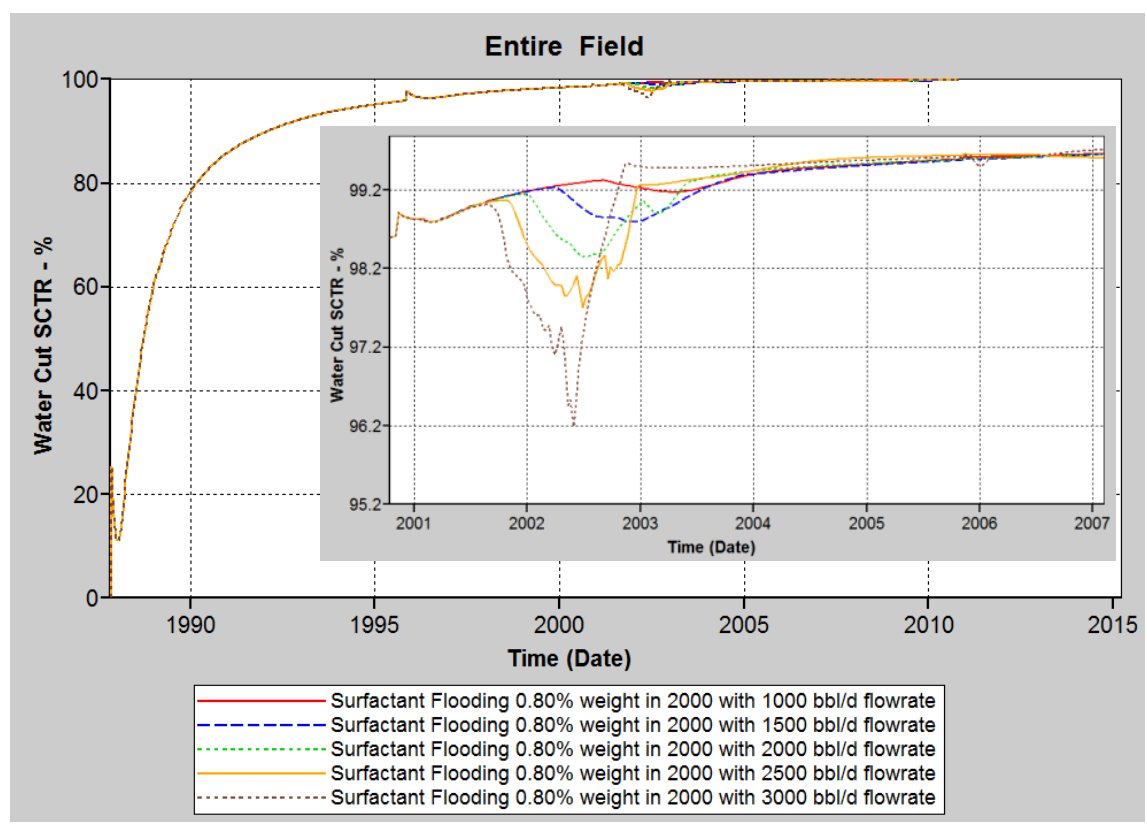

Figure3.18. Plot of water cut \% for different surfactant flooding flow rate

\subsubsection{Surfactant Flooding Period}

A sensitivity analysis on the surfactant flooding period is done. In the simulation to analyse the effect of period on oil recovery, the surfactant concentration is kept constant at $0.8 \%$ weight and flow rate of $3000 \mathrm{bbl} / \mathrm{day}$. Chase water is added for a year after surfactant flooding then the injector is shut in. Simulation periods are 3 years, 6 years and 9 years.

With regards to Figure 3.19, the longer the period of surfactant flooding, the greater the oil recovery. As the simulation is carried out with a constant flow rate and concentration, the volume of concentration can be evaluated similarly to the sensitivity analysis of flow rate. Hence, it can be deduced that with a greater volume of surfactant, more residual oil is managed to be produced after primary and secondary recovery. 


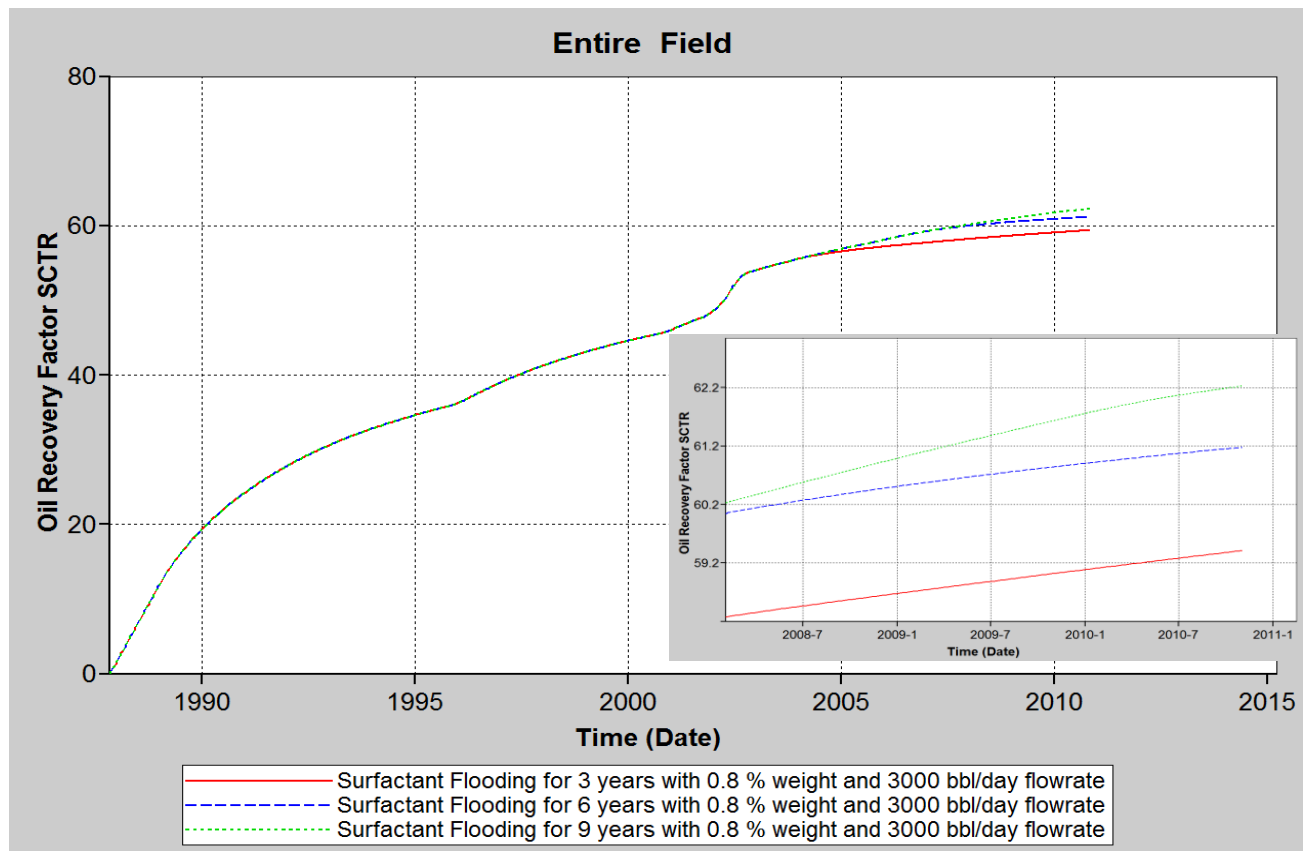

Figure3.19. Plot of oil recovery factor for different surfactant flooding periods

With higher amounts of surfactants, more oil is adsorbed by surfactant molecules. Thus, reducing the contact angle of solid surface and the oil-water interface, reducing the IFT even more. By this, the adhesion work of oil and solid surface and oil and water interface is reduced and the efficiency of oil displacement is increased. More surfactants will make the reservoir become more water-wet which is favourable for recovery. However, with a constant increase of period of 3 years in the analysis, the oil recovery does not reflect proportionally. After a certain amount, the system becomes saturated with surfactants at critical micelle concentrations (CMC).The interfaces of oil and water are wholly packed with surfactants and the oil recovery is more but the amount increase is less in total oil production. In regards of that, the optimum flooding period is chosen to be 6 years due to economical purposes. The pump to be run for 9 years is a very long period as it challenges the technical aspects. More cost has to be supplied to obtain a good standard and high-quality pump which can inject surfactants for a total of 9 years. Given that the increase from flooding for 6 years and 9 years is only $1 \%$ increase, the flooding period is chosen to flow optimally for 6 years with respects to the economics.

\subsection{Final Decision and Economic Aspect}

From all the simulation results obtained, the optimum conditions to produce oil from the given oil field are summarised in Figure 3.20.

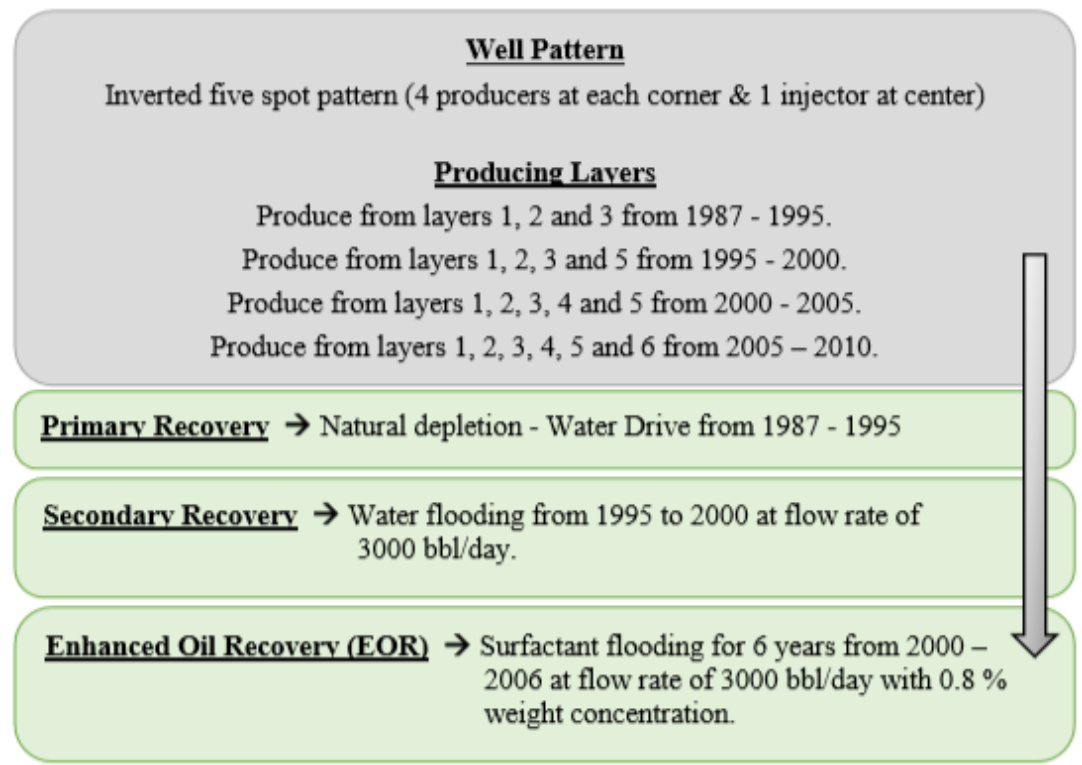

Figure3.20. Optimum conditions for all stages of oil recovery. 
Figure 3.21 and Table 3.1 depicts the total oil produce in percentage and in barrels for all stages of oil recovery under optimum conditions.

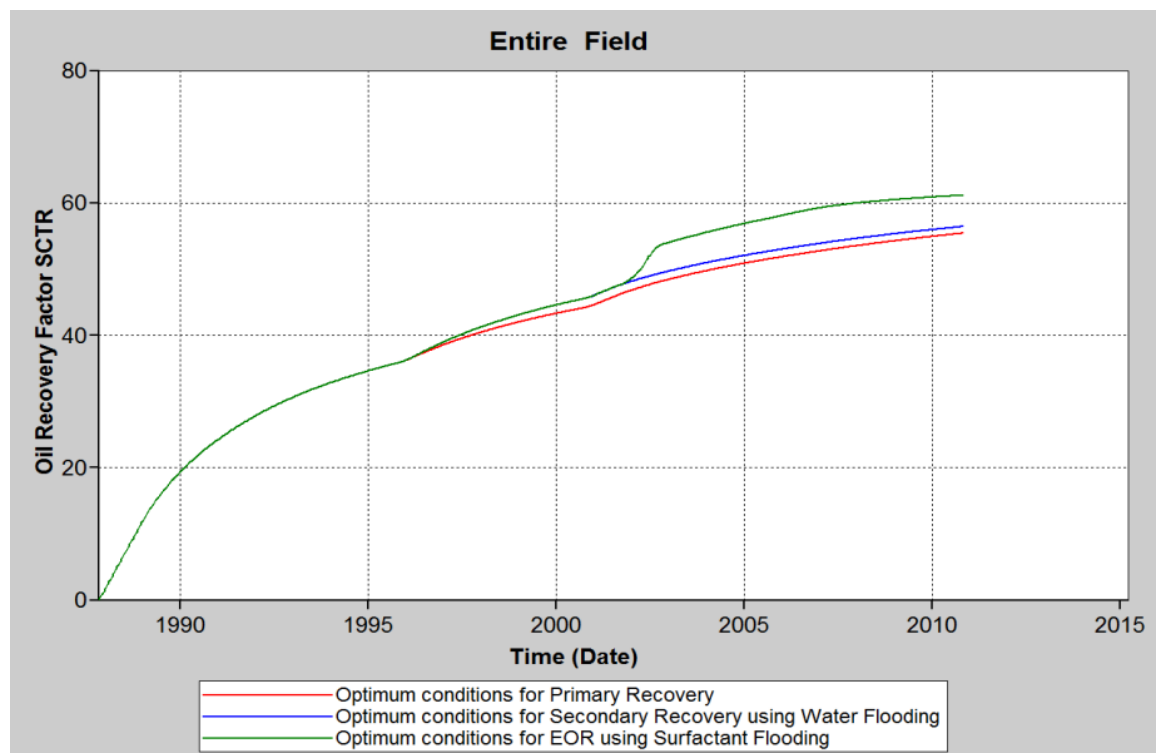

Figure3.21. Plot of oil recovery factor for each stage of oil recovery under optimum conditions

Table3.1. Numerical summary of oil recovery for different oil recovery stages at the end of reservoir production life (November 2010).

$\begin{array}{ccc}\text { Oil Recovery } & \text { Cumulative Oil } & \text { Difference in } \\ \text { Factor (\%) } & \text { Production (bbl) } & \text { amount (bbl) }\end{array}$

\begin{tabular}{|cccc|}
\hline Primary Recovery & 55.5 & $1,966,165$ & 0 \\
\hline $\begin{array}{c}\text { Secondary Recovery } \\
\text { by Water Flooding }\end{array}$ & 56.3 & $2,001,591$ & $+35,426$ \\
\hline $\begin{array}{c}\text { EOR by Surfactant } \\
\text { Flooding }\end{array}$ & 61.2 & $2,168,758$ & $+167,167$ \\
\hline
\end{tabular}

Surfactant flooding only recovers an extra of about $5 \%$ of oil originally in place. This value does not seem significant in percentage but if taken in volume of oil recovered perspective, surfactant flooding recovers extra of 167,167 barrels of oil. After surfactant flooding at optimum conditions there is still $38.8 \%$ of oil left behind in the reservoir. At this point, the interfacial tension between oil and water is no more the prominent issue. The field has an oil viscosity which is very high relative to water and a weak oil expansion. This reduces the sweep efficiency based on the theory of mobility ratio. To recover more than $61.2 \%$ of oil, the viscosity must be manipulated by other chemical flooding to achieve higher oil recovery. The injected fluid in STARS consists of surfact component and $\mathrm{Na}+$ component. Based on this, the type of surfactants used in this simulation is an anionic surfactant. Linear benzene alkyl sulfonates are common anionic surfactants used in petroleum production. According to www.alibaba.com this product average cost is USD 1000 for one tonne. The density of alkyl benzene sulfonate is $860 \mathrm{~kg} / \mathrm{m} 3$. Based on the simulation in STARS, the total mole fraction for surfact and Na components for concentration of $0.8 \%$ weight is 0.008195 .

From the final condition of EOR, surfactant is flooded at $3000 \mathrm{bbl} /$ day for 6 years. That equals to a total volume of $6,570,000$ barrels to be injected which is equivalent to $783,410 \mathrm{~m}^{3}$. With volume, density and mole fraction attained for alkyl benzene sulfonate, the mass needed for injection is approximately 5500 tonnes. This means a total of USD 5.5M needed to be spent to perform surfactant flooding. However, there is an extra of 167,167 barrels of oil recovered after surfactant flooding. Since the price of surfactant is based on May 2017, the average oil price on this date is taken to be at USD 50/barrel. This gives a total of USD $8.35 \mathrm{M}$. This concludes that surfactant flooding at the optimum conditions discussed would provide a benefit of USD $2.85 \mathrm{M}$. 


\section{CONCLUSION}

1. Surfactant flooding is a good potential method under chemical EOR. This is because it is proven to increase cumulative oil production after water flooding.

2. When concentration of surfactant is increased, the IFT values decreases. This is only up to a particular point which then the decrease is negligible and IFT values are constant. This point is the CMC where the system is saturated with surfactant monomers. The decrease of IFT values is related to the increase of the percentage of oil recovery. Lower IFT values will yield greater oil recovery and higher cumulative oil production.

3. The longer the flooding period of surfactants, the greater the oil recovery till the increase slowly decreases over longer periods. This is related to the same concept of the concentration of surfactants.

4. The increase of surfactant flowrate increases the velocity of displacing fluid. Thus, increasing the capillary number. Higher capillary number resorts to a greater oil recovery. However, if the flow rate is too high it is too costly and the oil recovery would drop because of shearing of the surfactant molecules.

5. In this reservoir, optimised primary and secondary recovery recovers $55.5 \%$ and $56.3 \%$ respectively of the OOIP. These values are high because of the very strong aquifer in the reservoir.

6. Depending on the nature of the reservoir, surfactant flooding has its certain degree of benefits. The main issue for this oil field is the high oil viscosity. As surfactants are not known to alter fluid viscosities, optimised surfactant flooding only provides roughly about $5 \%$ increase of oil recovery in this reservoir after optimised primary and secondary recovery methods.

\section{REFERENCES}

[1] Ahmadi, M. A., \&Shadizadeh, S. R. (2013). Implementation of a high performance surfactant for enhanced oil recovery from carbonate reservoirs. Journal of Petroleum Science and Engineering, 110, 6673. doi: 10.1016/j.petrol.2013.07.00

[2] AJ, V. (1996). Optimization of surfactant flooding: an economic approach. (Master's Thesis), The University of Texas at Austin, TX, Texas, U.S.

[3] Aslam, U. (2010). Numerical simulation of surfactant flooding in mixed wet reservoirs: University of Stavanger, Norway.

[4] Chaipornkaew M, W. K., Chantarataneewat W, Boontaeng, \& T, O. S., Maneeintr K (2013). Preliminary study of insitu combustion in heavy oil field in the North of Thailand. Proc Earth Planet Sci, 6, 326-334.

[5] Cooney, G., Littlefield, J., Marriott, J., \&Skone, T. (2015). Evaluating the Climate Benefits of CO sub (2) Enhanced Oil Recovery Using Life Cycle Analysis. Environmental Science \& Technology, 49(12), 74917491.

[6] E. Tzimas, A. G., C. Garcia Cortes and S.D. Peteves. (2005). Enhanced Oil Recovery using CO2 in the European Energy System European Commission Joint Research Centre

[7] Fathaddin, M., Buang, P., \&Elraies, K. (2010). Performance of Surfactant Flooding in Heterogeneous Two-Layered Porous Media. International Journal of Engineering Research in Africa, 1, 11-16. doi: 10.4028

[8] Han C, D. M., Sepehmoori K, Pope GA. (2007). A fully implicit, parallel, compositional chemical flooding simulator. SPE Paper 97217. SPE Journal, 12(3), 322-338

[9] Jin, B., Jiang, H., Zhang, X., Wang, J., Yang, J., \& Zheng, W. (2014). Numerical Simulation of SurfactantPolymer Flooding. Chemistry and Technology of Fuels and Oils, 50(1), 55-70. doi: 10.1007/s10553-0140490-8

[10] Kamal, M. (2016). A Review of Gemini Surfactants: Potential Application in Enhanced Oil Recovery. Journal of Surfactants and Detergents, 19(2), 223 236. doi: 10.1007/s11743-015-1776-5

[11] Karnanda, W., Benzagouta, M., AlQuraishi, A., \& Amro, M. (2013). Effect of temperature, pressure, salinity, and surfactant concentration on IFT for surfactant flooding optimization. Arabian Journal of Geosciences, 6(9), 3535 3544. doi: 10.1007/s12517-012-0605-7

[12] Morshedi, S., Foroughi, S., \&Beiranvand, M. S. (2014). Numerical Simulation of Surfactant Flooding in Darcy Scale Flow. Petroleum Science and Technology, 32(11), 1365-1374. doi: 10.1080/10916466.

2011.590839 
[13] Najafabadi, N. F., Delshad, M., Han, C., \&Sepehrnoori, K. (2012). Formulations for a three-phase, fully implicit, parallel, EOS compositional surfactant- polymer flooding simulator. Journal of Petroleum Science and Engineering, 86-87, 257-271. doi: 10.1016/j.petrol.2012.03.025

[14] Pope GA, N. R. (1978). Description of an improved compositional micellar/polymer simulator. SPE Paper 13976. SPE Journal, 18(5), 339-354.

[15] Rai, S., Bera, A., \& Mandal, A. (2015). Modeling of surfactant and surfactant- polymer flooding for enhanced oil recovery using STARS (CMG) software. Journal of Petroleum Exploration and Production Technology, 5(1), 1-11. doi: 10.1007/s13202-014-0112-3

[16] Rosen, M. J. (2012). Surfactants and Interfacial Phenomena (4th ed.). Hoboken: Hoboken: John Wiley \& Sons.

[17] Santos MD, N. A., Mata W, Silva JP. (2011). New Antenna Modelling using Wavelets for Heavy Oil Thermal Recovering Methods. Journal of Petroleum Science and Engineering, 76, 63-75.

[18] Sara BülowSandersen (2012). Enhanced Oil Recovery with Surfactant Flooding. (Ph.D), Technical University of Denmark, KongensLyngby, Denmark

[19] Smith, J., \& Cobb, W. (1997). Waterflooding (1st ed., pp. 4-6). Dallas, Texas: Mobil E\&P, Journal of Petroleum Technology.

[20] Yuan, C.-D., Pu, W.-F., Wang, X.-C., Sun, L., Zhang, Y.-C., \& Cheng, S. (2015). Effects of Interfacial Tension, Emulsification, and Surfactant Concentration on Oil Recovery in Surfactant Flooding Process for High Temperature and High Salinity Reservoirs. Energy \& Fuels, 29(10), 6165-6176. doi: 10.1021/acs.energyfuels.5b01393

[21] Zhang, S., Jiang, G.-C., Wang, L., Guo, H.-T., Tang, X.-G., \& Bai, D.-G. (2014). Foam Flooding with Ultra-Low Interfacial Tension to Enhance Heavy Oil Recovery. Journal of Dispersion Science and Technology, 35(3), 403-410. doi:10.1080/01932691.2013.792272

\section{AUTHORS' BIOGRAPHY}

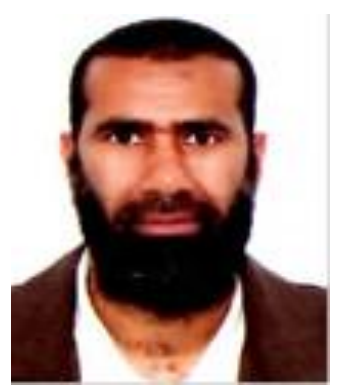

Hisham Khaled Ben Mahmud, has achieved Bachelor, Master and PhD degree in Chemical Engineering from Tripoli University, Sydney University and Curtin University, Australia, respectively. Also I have gained Graduate Diploma in oil and gas from University of Western Australia (UWA). I have expertise in modelling multiphase flow into subsea systems such as pipeline, jumper, riser evaluating pressure drop, and liquid holdup. Also optimize the risk of hydrate blockages into bend pipes. Recently I have involved into upstream research area including reservoir matrix acidizing, experimentally injecting a fluid (acid) into a core sample (sandstone or carbonate) to improve reservoir properties (porosity, permeability) observing wormhole and precipitation reaction. Another area I involve in is enhanced oil recovery (EOR) in brown oil field using different injecting fluids (CO2, water, polymer, surfactant) or modify production wells in order to improve hydrocarbon fluid recovery by minimizing oil wettability, surface tension and increase contact area.

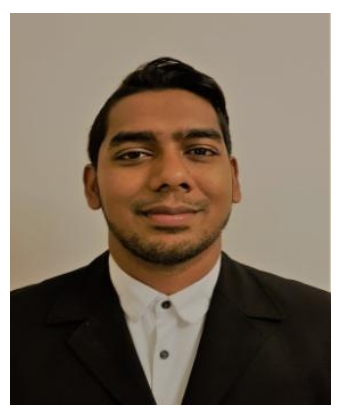

Brian Robin Stanislaus, Born on 23rd of March 1993 (24 years old) in Kuala Lumpur, but raised after birth in South Peninsular Malaysia in Johor. Primary School (SK Tebrau \& SK Bandar Seri Alam), Secondary School (SMK Dato' Penggawa Timur Masai), PreUniversity Studies (GCE A Levels @ Methodist College KL). Completed Bachelor's Degree in Petroleum Engineering in July 2017 from Curtin University Malaysia and conferred by the council with Upper Second Class Honours with CWA of 73.16\%. Currently (as of this date) unemployed and still in seek to begin career in the oil and gas industry. Share equal interest in the research and development as well as the practical and engineering side of the industry. Highly interested in music and sports such as football, futsal, marathon running, badminton, hiking, sailing.

Citation: Brian Robin Stanislaus and Hisham Khaled Ben Mahmud (2017). Numerical Approach for Enhanced Oil Recovery with Surfactant Flooding using STARS (CMG), International Journal of Petroleum and Petrochemical Engineering (IJPPE), 3(4), pp.1-18, DOI: http://dx.doi.org/10.20431/2454-7980.0304001

Copyright: (C) 2017 Brian Robin Stanislaus and Hisham Khaled Ben Mahmud. This is an open-access article distributed under the terms of the Creative Commons Attribution License, which permits unrestricted use, distribution, and reproduction in any medium, provided the original author and source are credited 